\title{
A Review of Plan Implementation Management Practices in the Bekwai Municipality in the Ashanti Region of Ghana
}

\author{
Mohammed Abubakari1, Gertrude Asokwah'1, Jonathan Mensah Dapaah², \\ Seth Christopher Yaw Appiah² \\ ${ }^{1}$ Department of Planning, College of Art and Built Environment, Kwame Nkrumah University of Science and \\ Technology, Kumasi, Ghana \\ ${ }^{2}$ Department of Sociology and Social Work, Kwame Nkrumah University of Science and Technology, Kumasi, \\ Ghana \\ Email: jmdapaah@hotmail.com, sychrist_2007@yahoo.com
}

Received 6 December 2015; accepted 4 June 2016; published 7 June 2016

Copyright (C) 2016 by authors and Scientific Research Publishing Inc.

This work is licensed under the Creative Commons Attribution International License (CC BY). http://creativecommons.org/licenses/by/4.0/

(c) (i) Open Access

\section{Abstract}

Implementation is very vital in planning. This crucial aspect of planning (implementation) can only be achieved when appropriate goals and definite objectives are translated into executable strategies. This study aims at evaluating projects planning, implementation and management processes in the Bekwai Municipal Assembly, highlighting their strength and weakness and coming out with recommendations to inform future policy formulation. The case study designs with a sampled population of 310 participants, involving 300 household heads and unit committee members who were enrolled for the study. The study purposively engaged 10 participants from key units within the Assembly's structure. The results of study demonstrate poor, unsatisfactory level of participation of concerned stakeholders at the grass root level in plan preparation and implementation. The study established that, statutory funding for the Assembly was not forthcoming. At the time of the conduct of the study, the District Assembly Common Fund, the major source of delegated funds for capital expenditures of the various MMDAs had been in arrears for over the past year. Notwithstanding these challenges, the Assembly has consistently been performing tremendously well in the FOAT (Functional Organizational Assessment Tool. Community level involvement in monitoring and evaluation of developmental projects was non-existing as none of the community members and unit committee members indicated their engagement in project monitoring and evaluation. Harnessing the resources potentials and opportunities of the Municipal remains the way forward towards expanding the revenue base of the municipality. Concerned stakeholder involvement is key to facilitating development. This could be done by adopting technologically inclined models such as mobile texting, employing the services of information vans and radio stations. The objective of realizing development project sustainability 
would be met if communities' level education is provided on the need for their participation in plan preparation, implementation and management in a symbiotic manner.

\title{
Keywords
}

\author{
Development, Experiences, Implementation, Ghana, Management, Participation, Practices, Plan
}

\section{Introduction}

The major essence of planning is its implementation aspect. This crucial component of planning can only be achieved or made possible when broad goals and definite objectives are translated into executable strategies. Plan implementation and its management do not only rest on the shoulders of planners but also other important actors and organizations such as community members, sub-structures such as Unit committees, Zonal and Area Councils, departments and units under the Assembly's structure. The essence of implementation in overall development processes has been echoed by Faludi (1976) and Conyers \& Hills (1984). In their opinion, implementation serves as the platform to converting the plans of an entity into projects or tangible benefits. The significance of Plan Preparation in terms of the overall development can never be overlooked in terms of plan implementation and sustainable development. Universally, the utility of plan as tools for facilitating development is never disputed (Frimpong, 2012; Goetz cited by Goel, 2003). Plans are functional tools for accelerating socio-economic developments because they provide direction, focus and sense of imagination. The absence of a well-designed plan breeds a development environment where untimely changes in focus, duplication of efforts and programme inconsistencies are the results. Frimpong (2012) explains development plan to constitute paper presentation that details precisely purposeful goals, with stated objectives and programmes of an organisations, local authority and countries. It usually has a time frame within which the indicators are to be realized.

The National Development Planning Commission is the national planning body that has oversight responsibility on planning issues in Ghana. According to the National Development Planning Commission (2013), the steps that should be followed in preparing development plans in Ghana include first; stating the vision, the mission and the functions of the concerned body. This should then be followed by Performance review. Performance review considers looking at past achievements and mistakes and learning lessons from them to inform current plan preparation process. It is very vital to note that the assessment of past performance should embrace the extent of projects' implementation as to whether they are fully implemented, suspended/abandoned, ongoing, not implemented and implemented but not in the Medium Term Development Plan. The third step as indicated by the NDPC is Compilation of profile of the various sectors such as the agricultural sector, the health sector, the education sector and the transport sector amongst others. At this very step, the institutional capacity should be taken into key consideration as well as cross-cutting issues such as HIV/AIDs. The other steps include Transition from the Ghana Shared Growth and Development Agenda (GSGDA) 2010-2013 to the New Medium Term Development Plan Framework 2014-2017, Prioritization, Goals formulation, Adoption of Policy Objectives and strategies, Formulation of development programmes and sub programmes, developing strategies, preparation of Programme of Action and preparation of indicative Financial Plan.

In plan preparation process, its implementation and management, the relevance of participation has been pinpointed as very crucial in development (Jennings, 2000). From the viewpoint of Nghikembua (1996), the participation of concerned stakeholders will empower them to mobilize resources, make decisions and control activities that affect their lives (Moynihan, 2007). The empowerment of people will serve as motor to promote change in decision-making chain and will break the existing power structures that impede communities' participation in plan preparation, implementation and management (Friedmann, 1992, cited in Mohan \& Stokke, 2000).

In Ghana, the concern for the involvement of local people in implementation of development plans has been well embraced but its practices have received several hitces. Many development challenges which various plans seek to address continue to exist in widespread quantities (Frimpong, 2012). Thus, developing plans appear to have become ritualized. However, Frimpong study in the Asante Akyem south district established that only ten out of the 75 earmark projects within the stipulated periods which represented 13.3\% had not been completed. At the time of the study, one in every four of the earmarked projects was still on-going. Noncompliance to bud- 
getary plans characterized more than a tenth (12\%) of the projects. Excess in budgetary allocation was between $105 \%$ and $400 \%$. This shows inconsistency in achieving planned developments.

Though there is a shift in paradigm in Ghana where the top-down approach to development has been replaced by bottom-up approach; the model seems to be used only in theoretical terms but not in practicality. This explains why Moynihan (2003: p. 62) acknowledges that effective strategies in beneficiary participation in community-based projects and plans are yet to be fully understood by development actors in Ghana. Thus, social accountability emerges as problematic. This paper seeks to examine the plan implementation and management experiences of the Bekwai Municipality which is located in the Ashanti region of Ghana.

\section{Methods}

\subsection{Study Design and Population}

A case study involving qualitative method was undertaken among purposively selected communities in the Bekwai Municipality. The overarching purpose of a case study is to understand phenomenon that is unique to an identify case, thus the Bekwai Municipality. Yin (2009) elaborates that, case study enables the researcher to study a phenomenon in detail and provide objectivity within the limited period. Therefore, case study provides an opportunity to study a phenomenon within a geographical boundary.

\subsection{Study Setting}

The study was conducted in the Bekwai Municipal Assembly. The Bekwai Municipal is one of the twenty-seven (27) administrative Districts in the Ashanti Region of Ghana, established under legislative instrument (L.I. 1906, 2007). Bekwai is the administrative capital of the Municipality. The 2010 population and housing census (Ghana Statistical Service, 2010) puts the population of the Municipal at 118,024 with a growth rate of $3.1 \%$. Females constitute the dominant sex in the district constituting 52.9\% while males make up 47.1\%. The Bekwai Municipal Assembly is amongst the top-most MMDAs (Metropolitan, Municipal and District Assemblies) which performs tremendously under the government's Functional Organizational Assessment Tool (FOAT) over the past three years.

\subsection{Sampling and Data Collection Procedures}

A total of 300, constituting 275 household heads and 15 unit committee members with three members selected from five communities in the municipality were enrolled for the study. The sampled population included household heads and unit committee members in the five selected communities. To avoid biased representation, the researchers conveniently sampled respondents based on the population of the communities; thus, community with the highest population has the greatest sample size. The five communities were purposively selected from the municipality based on the number of projects implemented in the community (level of development in the communities) within the planned period of 2010-2015. The selected communities were Bekwai; the capital, Ofoase Kokoben, Kokofu, Anwiankwanta and Amoafu. Apart from that, key units within the Assembly's structure were also purposively selected. In all, 10 participants from the key units were sampled. The Units were Municipal Planning and Coordinating Unit (MPCU), the Planning Unit, the Town and Country Planning Unit and the Finance Department. The study adopted the single population proportion formula to calculate the required sample size.

$$
\text { Thus } n=\frac{Z^{2} p q D}{d^{2}}
$$

$n=$ desired sample size of the population, applicable with study population more than 10,000.

$Z=$ the standard deviate, usually 1.96 which corresponds to $95 \%$ confidence level.

$p$ = proportion of the target population estimated to have the particular characteristics under the study. In this case 30 per cent is estimated to be involved in participation in the plan implementation process. This was based on informal observation in most district and municipal assembly in the region resulting from the researchers practical experience whiles engaging the assembly's.

$$
\begin{aligned}
& p=0.30 . \\
& q=1-p, \text { i.e. } 1-0.30=0.70 .
\end{aligned}
$$


$d=$ Degree of accuracy usually (0.05).

$D=$ design effect usually 1 where there are no replications or comparisons.

$$
\text { Thus } n=\frac{1.96^{2} \times 0.30 \times 0.70 \times 1}{0.05^{2}}=322
$$

However, after editing the response and eliminating blank responses, 310 respondents representing $96.2 \%$ of the study participants were enrolled.

Data was collected using household questionnaire within each sampled household. In all there were 23 items in the household questionnaires. Variables included in the household questionnaires were socio-demographic variables of age, ethnicity, educational level, marital status, religion and literacy level. Others such as awareness of development projects, medium of becoming aware of development projects, ability of the project to solve the developmental need of the community, awareness of abandoned projects, participation in the project implementation, medium of participation and maintenance of projects. The scoring of the responses was based on pooled frequencies from the study participants. In the interviewed households family heads and Unit committee members in the selected communities were identified for individual interview. The data collection took the face to face interview approach. The additional data that complemented the household survey was the application of capacity self-assessment sheet using a modified Organizational Capacity Assessment Tool (OCAT). Thus through a triangulation approach, the researchers elicited data from multiple sources using different data collection instruments. These sources included Local Government publications and the medium term development plan (2012-2015) of the assembly. Table 1 presents the sample distribution according to the communities selected and the panning unit.

\begin{tabular}{cc} 
Table 1. Selected communities and their respective sample sizes. \\
\hline Communities & Sample Size \\
\hline Bekwai & 75 \\
Ofoase Kokoben & 65 \\
Kokofu & 60 \\
Anwiankwanta & 50 \\
Amoafu & 50 \\
MPCU & 10 \\
Total & $\mathbf{3 1 0}$ \\
\hline
\end{tabular}

\subsection{Statistical Analysis}

The study results have been analyzed in both qualitative and quantitative terms (Triangulation approach). Data collected have been analyzed descriptively using tables. The responses and findings were converted to percentage scores to serve as units of measurement of results and findings of the study. Qualitative data was also considered during data analysis and have been presented as quotes with emerging themes.

\subsection{Ethical Issues}

The study did not elicit information that were harmful or injurious to the human subjects. Notwithstanding, informed consent was sought from the study participants. The participants were asked to indicate their consent either verbally or offer written consent before the commencement of the study. Study participants were briefed about their decision and willingness to decline in participation at any point in time during the conduct of the study.

\section{Results}

\subsection{Assessment of the Plan Preparation Process of the Bekwai Municipal Assembly}

Assessing the plan preparation process is very important because it gives a clue as to whether the Bekwai 
Municipal Assembly followed the process in plan preparation outlined by the National Development Planning Commission (NDPC). The study adopted conformity (whether the process followed is in line with the guidelines of the NDPC) and Participation (the degree of involvement whether direct or indirect of various stakeholders in the municipality) as criteria for the assessment of the plan preparation process.

Table 2 indicates the process outlined by the NDPC (Mother planning body for Ghana) in plan preparation process and the extent to which the Bekwai Municipal Assembly duly followed the outlined process. After the assessment of the plan preparation process using both primary (field survey) and secondary data sources (NDPC Guidelines, GPRS II Policy document, GSGDA I, Annual Progress Report and the Medium Term Development Plan of the Municipality, the researchers identified the strengths and weaknesses of the Municipal Assembly. In terms of strengths; the Assembly has a qualified planner (someone who has pursued Bsc Development Planning), thus, the Assembly does not need the services of any facilitator as advised by the NDPC. Again, the Municipal Development Goals were formulated in the light of GSGDA, MDGs, NEPAD and the priorities of the Municipal Assembly.

In line with the weaknesses, it was identified that the Municipal Chief Executive (Political Appointee) served as the Chairman and the leader of project implementation team instead of the Municipal Coordinating Director as recommended by NDPC. Again, institutions whose inputs are very vital in plan preparation process such as the Social Welfare and Community Service Department were under-funded.

\subsection{SWOT Analysis of Municipal Planning Coordinating Unit-The Main Body Concerned with Plan Implementation}

Table 3 shows the SWOT Analysis of the Municipal Planning Coordinating Unit of the Bekwai Municipal Assembly. The results (as in Table 3) affirmed that the Bekwai Municipal Assembly has highly trained staff (the least qualification was degree) who are experienced (have worked within the public sector for more than five years) and dedicated to their work. However, about $65 \%$ of the staff members were not abreast with ICT. There is therefore a clarion call for an effective ICT training programme to be instituted by the government. Financial and technical supports from external bodies are available which can be harnessed to promote development. There is however delays in the release of such fund especially the District Assembly Common Fund (DACF) which has been in arrears for a year as at the time of the study.

\subsection{Gap Analysis of the Extent of Project Implementation by the Bekwai Municipal Assembly}

The study investigated into the extent of implementation of projects in 2 out of the 5 selected communities within the year 2015. This was done using Gap Analysis as indicated in Table 4. The results indicated that the Bekwai Municipal Assembly has been able to start and complete one project in Kokofu. In Bekwai, however, the planned project was not implemented due to unfavorable weather condition that previously affected the first phase of that project.

\subsection{Participation of Community Members and Unit Committees (a Sub Structure) in Projects Implementation}

The findings that relates to community level participation have been presented in Table 5. Gap analysis was also conducted to assess the extent of participation of community members and Unit committees (sub structure) in plan implementation

At the plan preparation less than half of all unit committee members were engaged. This did not prevent the full participation of Unit committee members during the implementation phase. In terms of monitoring, in quite an unsatisfactory manner, no community member was engaged in the monitoring and evaluation of the projects. This raises a major issue as far as social accountability is concerned.

\subsection{Factors Affecting Plan Implementation in Bekwai Municipality}

Plan Implementation is affected by a lot of factors which could be both internal and external ranging from economic conditions, institutional weaknesses and even political interferences (Todaro, 1997; Killick, 1981; Ayayee, 1993). The study embraced PESTELLI Analysis (Political, Economic, Socio-cultural, Technological, Environ- 
mental, Legal and Institutional factors) to assess the factors the influence plan implementation in the study communities within the municipality.

\section{Table 2. Assessing the plan preparation process followed by the Bekwai municipal assembly.}

\begin{tabular}{|ccc|}
\hline $\begin{array}{c}\text { Process outlined by the } \\
\text { NDPC guidelines }\end{array}$ & Criteria & \\
\cline { 2 - 3 } & Conformity & Participation \\
\hline
\end{tabular}

Performance review

Compilation of profile

Linking harmonized identified development programmes/ issues to Ghana Shared Growth and Development Agenda (GSGDA)

POCC analysis (potentials, opportunities, constraints and challenges)

Formulation of goals and development projections

Development of objectives and strategies

Development programmes and composite programme of action

Annual plans and indicative financial plan
Programmes and activities were reviewed in relation to the Growth and Poverty Reduction Strategy (GPRS II).

Plan Review took into consideration new projects, interventions and initiatives such as free maternal care programme and reduction in child labour as stipulated in the NDPC Guidelines.

Cross cutting issues such as HIV/AIDs plan were implemented by the municipality but their performances were not reviewed.

The Municipal Planning Coordinating Unit (MPCU) compiled the profile of the municipality as outlined in the NDPC Guidelines.

Harmonization of development issues with GPRS II and GSGDA was duly conducted as stipulated in the NDPC Guidelines.

Identified prioritized issues were subjected to the Analysis of POCC in the context of the Municipality.

Municipal Goals were formulated in the light of the National Goal as stipulated in the NDPC Guidelines.

Objectives and their strategies aimed at achieving the goal of the Municipality were done as directed by the NDPC Guidelines.

The composite programme of Actions was grouped under the thematic areas of GSGDA with the location, indicative budget, funding agencies, implementing and collaborative agencies and also agencies for monitoring and evaluation

Promoting Dialogue and Feedback Mechanism was used as a means to obtain information from the grass root level. Other concerned stakeholders were involved through the dissemination of Municipal Medium Term Development

Plan and Annual Progress reports to sub structures.
Participation of sub-structures was not enough since $54.5 \%$ were not involved. This is a deviation from the guidelines which inquire that all sub-structures should be involved in performance review.

Various units and departments within the Assembly's structure were considered in conducting the profile of the municipality

(About 95\% participation of sub structures and $100 \%$ participation of units and departments such as Finance, Agricultural, Health, Education and others).

The views of sub structures were duly consulted (95\% participated). Community members were indirectly involved since the sub structures served as their reps in terms of their participation.

Community members (about 68\% of community members) contributed to the potentials and constraints that may help or hinder plan implementation.

Policy documents from NEPAD and

APRS were duly considered in the formulation of the Municipality's goal.

Developing objectives and strategies was highly technical, thus, community members and sub structures were not consulted. Various departments and units developed their respective objectives and strategies to help address development issues.

There was the involvement of traditional sources of funding (i.e.; the DACF, IGF), development partners such as AfDB, JICA and the Netherlands Government among others such as NGOs in the Municipality. About 58.5\% of community members affirmed that they contributed cash/kind to implement projects in the plan

Departments and Units within the Assembly's structure were involved in the preparation of Annual Plans affirmed by the MPCU. 
Table 3. Strengths, Weaknesses, Opportunities and Threats (SWOT) analysis of MPCU (the main body concerned with plan implementation).

\begin{tabular}{lllll}
\hline \multicolumn{1}{c}{ Strengths } & \multicolumn{1}{c}{ Weakness } & \multicolumn{1}{c}{ Opportunities } & Threat \\
\hline - Highly trained staff & & Financial and logistics & \\
- $\begin{array}{l}\text { Experienced staff } \\
\text { Dedicated and committed } \\
\text { staff }\end{array}$ & $\begin{array}{l}\text { 65\% staff are not abreast } \\
\text { with ICT skills and } \\
\text { modern technology }\end{array}$ & $\begin{array}{l}\text { as JICA } \\
\text { Technical support from } \\
\text { donors }\end{array}$ & Delay in the release of \\
& & funds & \\
\hline
\end{tabular}

Table 4. Gap analysis of the extent of project implementation by the bekwai municipal assembly. (Two communities considered).

\begin{tabular}{|c|c|c|c|c|c|c|}
\hline Project & Location & $\begin{array}{c}\text { Expected starting } \\
\text { period }\end{array}$ & $\begin{array}{c}\text { Actual starting } \\
\text { period }\end{array}$ & $\begin{array}{c}\text { Current } \\
\text { status }\end{array}$ & Gap & Remarks \\
\hline $\begin{array}{c}\text { Construction of } \\
1 \text { no. } 12 \text { seater } \\
\text { aqua privy }\end{array}$ & Kokofu & 1/01/2013-31/12/2013 & $21 / 2 / 2013-21 / 06 / 2013$ & Completed & - & $\begin{array}{l}\text { Successful } \\
\text { implementation } \\
\text { of projects }\end{array}$ \\
\hline $\begin{array}{l}\text { Construction of } \\
\text { culvert and drains } \\
\text { and rehabilitation } \\
\text { of Mrs. Lamptey’s } \\
\text { road (phase 2) }\end{array}$ & Bekwai & 1/01/2013-31/12/2013 & - & Not started & $\begin{array}{l}\text { Project not } \\
\text { implemented } \\
\text { as planned } \\
\text { by the } \\
\text { assembly }\end{array}$ & $\begin{array}{l}\text { Unfavorable weather } \\
\text { condition impeded the } \\
\text { first phase of the } \\
\text { project and this } \\
\text { affected the } \\
\text { commencement of } \\
\text { the second phase }\end{array}$ \\
\hline
\end{tabular}

\subsection{Political Factors}

Data collected from the field (household) indicated that 40 out of the 300 participants from the communities excluding those in the planning unit attested that political factors influence plan implementation and management in the municipality. This represented $13.3 \%$ of the total number of community respondents. The political factor were; the influence of change of government and governmental neglect of the municipality (11.2\%), influences of political division of households, change in the Municipal Chief Executive (1.2\%) and political divisions of members of sub-structures (0.9\%). A respondent from Ofoase Kokoben for instance indicated that

"We have differences in political affiliations which inhibit the work of the municipal assembly".

\subsection{Economic Factors}

In the opinion of $14.7 \%$ (44/300) community respondents, economic factors mitigate the smooth functioning of the Municipal. The greater proportion of the community members within the municipal did not consider the Assembly to be economically challenged. The Bekwai Municipality shares borders Lake Bosomtwe with the Bosomtwe Atwima Kwanwoma District. Revenue generated from the tourist site is used to facilitate plan implementation in the Municipality. The FOAT (Functional Organizational Assessment Tool) which is a performance base tool was used to assess the performance of the Municipality within the Planned Period. The Municipality upon the performance assessment qualified for the Urban Development Grant (UDG). This facilitated the plan implementation process. Thus economically, the municipal performs above average.

\subsection{Socio-Cultural Factors}

In terms of socio-cultural factors, 14 respondents confirmed that they affect plan implementation management in the municipality. This represented approximately $4.8 \%$ of the total number of respondents who expressed their opinions in this direction. A respondent attested that

"Chieftaincy issues affect project implementation in this community"...

Another added that;

"Communal labour is cherished value in the community". Thus, they are forced to be involved in some projects implemented in the community. 
Table 5. Extent of participation of community members and unit committees (a sub structure) in projects implementation.

\begin{tabular}{|c|c|c|c|}
\hline \multicolumn{4}{|c|}{ Unit committee (In selected communities) } \\
\hline $\begin{array}{l}\text { Stages involved in } \\
\text { bringing out } \\
\text { comprehensive } \\
\text { development plan }\end{array}$ & $\begin{array}{l}\text { Extent of participation } \\
\text { (actual participation) }\end{array}$ & Gap identified & Remarks from team/researchers \\
\hline Plan preparation & $\begin{array}{l}45.5 \% \text { of unit committees } \\
\text { considered in the study were } \\
\text { involved in Plan preparation }\end{array}$ & $\begin{array}{l}54.5 \% \text { of the unit } \\
\text { committees were not } \\
\text { involved in Plan } \\
\text { preparation }\end{array}$ & $\begin{array}{l}\text { Inputs from the unit committees are } \\
\text { necessary; thus, the need for the } \\
\text { Assembly to consider the unit } \\
\text { committees in plan preparation }\end{array}$ \\
\hline Implementation & $\begin{array}{l}\text { Plays collaborative roles in plan } \\
\text { implementation ( } 100 \% \\
\text { involvement in terms of } \\
\text { implementation) }\end{array}$ & -- & $\begin{array}{l}\text { The assembly needs to be } \\
\text { recommended for full involvement } \\
\text { of unit committees in project } \\
\text { implementation }\end{array}$ \\
\hline $\begin{array}{l}\text { Monitoring and } \\
\text { evaluation }\end{array}$ & $\begin{array}{l}\text { Supervisory role through daily } \\
\text { on-site inspection. } 81.8 \% \text { were } \\
\text { involved in monitoring while } 18.2 \% \\
\text { were involved in evaluation }\end{array}$ & $\begin{array}{l}18.2 \% \text { gap in terms of } \\
\text { monitoring while } 81.8 \% \\
\text { gap in terms of evaluation }\end{array}$ & $\begin{array}{l}\text { The gap could be attributed to the } \\
\text { logistical problems faced by the Unit } \\
\text { committees. This implies that unit } \\
\text { committees should be provided with } \\
\text { logistics so as to undertake } \\
\text { monitoring and evaluation }\end{array}$ \\
\hline \multicolumn{4}{|c|}{ Community members } \\
\hline Plan preparation & $\begin{array}{l}22.3 \% \text { of community } \\
\text { members were aware of plan while } \\
26.5 \% \text { were involved } \\
\text { in plan preparation }\end{array}$ & $\begin{array}{c}77.7 \% \text { of community } \\
\text { members not aware of } \\
\text { plan while } 73.5 \% \text { were } \\
\text { not involved in plan } \\
\text { preparation }\end{array}$ & $\begin{array}{l}\text { The views of community members } \\
\text { need to be solicited in terms of plan } \\
\text { preparation }\end{array}$ \\
\hline Plan implementation & $\begin{array}{l}44.4 \% \text { were involved in plan } \\
\text { implementation }\end{array}$ & $\begin{array}{l}55.6 \% \text { of community } \\
\text { members were not } \\
\text { involved in plan } \\
\text { implementation }\end{array}$ & $\begin{array}{l}\text { Communities' involvement in plan } \\
\text { implementation is essential since it } \\
\text { ensures sustainability of projects. This } \\
\text { calls for need for the Assembly to } \\
\text { involve communities }\end{array}$ \\
\hline $\begin{array}{l}\text { Monitoring and } \\
\text { evaluation }\end{array}$ & $\begin{array}{l}0 \% \text { of community members were } \\
\text { involved }\end{array}$ & $\begin{array}{l}\text { 100\% gap in terms of } \\
\text { community participation } \\
\text { in monitoring and } \\
\text { evaluation }\end{array}$ & $\begin{array}{l}\text { The MPCU should endeavor to } \\
\text { involve community members in } \\
\text { monitoring and evaluation } \\
\text { since they could provide } \\
\text { valuable inputs to inform } \\
\text { project implementation }\end{array}$ \\
\hline
\end{tabular}

\subsection{Technological Factors}

At the community level, 14 participants involving household heads and unit committee members held the opinion that technological factors influence plan implementation management in the municipality. A respondent indicated that

"Information sharing on projects to facilitate awareness of such projects is very poor"...

He recommended that, the community leaders should utilize information centre (a technological approach) as a means to share information on project awareness, involvement and maintenance.

\subsection{Environmental Factors}

In terms of environmental factors, only $2.6 \%$ of respondents agreed to it. This represented 8 out of a total number of respondents shared that they were situated in favourable environment that predisposes them to take advantage in facilitating the implementation of plans. One respondent from Ofoase Kokoben for instance indicated that: 
"Vast land is available for implementation of physical projects in this community".

\subsection{Legal Factors}

The operations of the various sub-district structures that play instrumental role in plan implementation and its management are backed by the Local Government (Urban, Zonal, Area and Town Councils and Unit Committees) Establishment Instrument, 1994, (L.I. 1589). The legal instrument establishing the Bekwai Municipality is L.I. 1906, 2007. The District Assembly Common Fund (DACF) is established by Article 252 of the 1992 constitution. The presence of Financial Administration Act (Act 654), 2003 and Procurement Act (Act 663), 2003 has guided the Municipal Assembly to use financial resources judiciously for plan implementation and management. There is also a District Court in the Municipality (Bekwai) which enforces bye-laws and settles disputes. This has influence plan implementation in a positive direction in the municipality.

\subsection{Institutional Factors}

In terms of institutional factors, only $1.3 \%$ of the community level participants hold the view that such factors influence plan implementation management in the municipality. Thus, community level do not see any institutional barriers and challenges with the municipality as far as plan preparation and implementation is concerned. This is however a contrast between what the community level participants think and what the real institutional challenges are from the technocrats. From the perspective of the sub-district structures, they indicated that they are logistically constrained which affects them in terms of their contribution to plan implementation management. In terms of capacity, the Municipal Assembly has a qualified and professional planner who gives technical advice in terms of plan implementation and management in the municipality. The major challenge from an institutional perspective is logistics challenge.

\section{Discussions}

Development Plans are very important since they serve as guidelines to steer development affairs of a particular locality. This calls for the need for comprehensive stakeholder participation in plan preparation, implementation and management (NDPC, 2014-2017; Jennings, 2000). An assessment of plan preparation process of Bekwai Municipality revealed that in terms of performance review, the participation of sub structures was $54.5 \%$ while in terms of compilation of the profile, 95\% sub structures were involved while Departments and Units were fully considered. This finding lay credence to Moniyan (2003) finding that participation in its general terms seem not to be understood by development actors since in some cases they appreciably involve stakeholders, whist sometimes stakeholders are poorly engaged in development process. From the findings of this study, we identified social accountability to be almost negligible in terms of monitoring and evaluation. Very unique to this study was the fact that no community level participant, even with the unit committee members considered themselves as ever being part of monitoring and evaluation of development projects.

Another finding from the study was the logistical constraints faced by the Assembly and the poor knowledge of the masses in ICT-skills and ideas. This calls for the need for the government to institute periodic training programmes which can help improve the knowledge of staff in ICT. The government also delays in the funds that are expected to be given to the Assembly every year. The need for government to provide financial inputs on timely basis can help to facilitate the current development process of the municipality. Using the gap analysis indicated that in plan preparation, there was $54.5 \%$ gap of sub structures and $73.5 \%$ gap of community members. This finding is consistent with the findings of Frimpong (2012).

The study revealed that $77.7 \%$ of community members were not even aware of the plan preparation process. Again, despite the full participation of sub structures in plan implementation, 55.6\% of community members were not involved in plan implementation. In terms of plan management using monitoring and evaluation process, $18.2 \%$ sub structures did not participate while the entire community members also disengaged in Monitoring and Evaluation. This was due to the presumptions that the participation of sub structures implies the indirect participation of community members and also community members have little knowledge in terms of monitoring and evaluation. These presumptions may be true; however, to ensure sustainable development, the Assembly needs to go the extra-mile to involve the people themselves when possible. This is because, participation will empower both the sub-structures and community members to promote change and provide vital inputs 
(Nghikembua, 1996; Friedmann, 1992) to inform the development of the municipality. Our study makes a case for going beyond sub structure member representation and participation in plan preparation and implementation to a holistic involvement of community members at the plan formulation stage to its monitoring and evaluation stage. This will ensure social accountability and facilitate community ownership of developmental projects, a toll necessary for project and sustainable development.

\section{Limitation}

The study is limited by the fact that community members may generally not have technical competence in understanding the project cycle as far as projects are implemented. This might have given them a somewhat negative appraisal of the development projects. However, the triangulation of the evidence through the adoption of multiple sources of data collection validates the findings of this paper. Similar study should explore eliciting data randomly without limiting it to household heads who may not adequately represent the views of the larger community.

\section{Conclusion}

Collaborative plan preparation, implementation and management undeniably lead to sustainable development since all and sundry feel part of the entire development process. The assessment process revealed weak grass root participation and effective participation of stakeholders at the topmost structure of the Assembly. Though, the inputs of the top structures are vital, individuals at the grass root levels are those who are in direct contact with the development issues facing the municipality; thus, their inputs are more valuable and should not be taken-out. Government support in the form of finance and technical expertise will serve as catalyst to promote the current state of the municipality.

\section{Competing Interests}

The authors declare no competing interests.

\section{References}

Ayayee, D. K. (1993). Techniques for Plan Implementation and Monitoring. National Development: Problems, Solutions, Strategies. Proceedings of the Ghana Academy of Arts and Sciences, xxx, 15.

Conyers, D. \& Hills, P. (1984). An Introductory to Development Planning in Third World. New York.

Faludi, A. (1976). Planning Theory. Oxford: Pergamos Press, A. Wheaton and Co. Exetor.

Friedmann, J. (1992). Empowerment: The Politics of Alternative Development. Oxford: Blackwell.

Frimpong, K. (2012). Managing Plan Implementation in the Asante Akyem South District Assembly: Capacity Issues and Challenges, Journal of Science and Technology, 32, 117-129. http://dx.doi.org/10.4314/just.v32i1.12

Ghana Statistical Service (2010). Ghana Demographic Health Survey Report. Accra.

Goel, S. L. (2003). Public Administration Theory and Practice. New Delhi: Deep \& Deep Publications PVT Ltd.

Jennings, R. (2000). Participatory Development as New Paradigm: The Transition of Development Professionalism. Paper prepared for the Community Based Reintegration and Rehabilitation in Post-Conflict Settings Conference, Washington DC, 5 October 2000, 20-21.

Killick, T. (1981). Policy Economics. A Textbooks of Applied Economics and Developing Countries. London. Heinemann Educational Books Ltd.

Mohan, G., \& Stokke, K. (2000). Participatory Development and Empowerment: The Dangers of Localism. Third World Quarterly, 21, 247-268. http://dx.doi.org/10.1080/01436590050004346

Moynihan, D. P (2007). Citizen Participation in Budgeting: Prospects for Developing Countries. In W. B Anwar Shar (Ed.), Local Public Financial Management, WB.

Moynihan, D. P. (2003). Normative and Instrumental Perspectives on Public Participation Citizen Summits in Washington DC. The American Review of Public Administration, 33, 164-188. http://dx.doi.org/10.1177/0275074003251379

National Development Planning Commission (NDPC) (2013). Guidelines for the Preparation of Medium Term Development Plans by Ministries, Departments and Agencies 2014-2017. Accra.

Nghikembua, S. (1996). From Drought-Relief Recipients to Community-based Development Organizations; A Case of Par- 
M. Abubakari et al.

ticipation in Human Settlement Development. Namibia: Windhoek, Multi-Disciplinary Research Centre, University of Namibia.

Todaro, M. P. (1997). Economic Development. Reading, MA: Addison Wesley.

Yin, R. K. (2009). Case Study Research: Design and Methods (Vol. 5). New York: Sage Publications. 